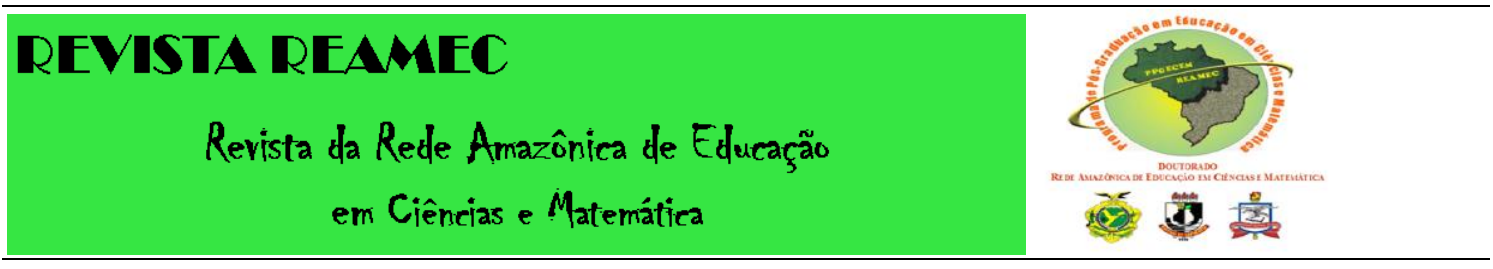

\title{
EDUCAÇÃO FINANCEIRA: UM COMPARATIVO ENTRE ESTUDANTES DE ESCOLAS PÚBLICAS E PRIVADAS
}

\author{
FINANCIAL EDUCATION: A COMPARISON BETWEEN HIGH SCHOOL \\ STUDENTS OF PUBLIC AND PRIVATE SCHOOLS
}

Rosangela Ramon
Eliane Trevisan

\begin{abstract}
RESUMO
A Educação Financeira é um tema pouco explorado no Brasil. Evidência disso é que uma quantidade significativa de pessoas não teve acesso à Educação Financeira no seu processo de formação e não possui o hábito de realizar planejamento financeiro. Como consequência, muitos brasileiros convivem com problemas relacionados a finanças. A partir desse contexto, o artigo apresenta um embasamento teórico sobre o tema e o resultado de uma investigação, com estudantes de ensino médio, sobre planejamento orçamentário, orçamento doméstico, hábito de poupar, entre outros, na qual as respostas fornecidas pelos estudantes de duas escolas públicas e duas privadas são comparadas. Os resultados da pesquisa mostram que os estudantes se comportam de forma semelhante. Pode-se ainda concluir que não utilizam os conceitos de Educação Financeira no seu dia a dia.
\end{abstract}

Palavras chave: Educação Financeira. Ensino Médio. Comparativo escolas públicas e privadas.

\begin{abstract}
Financial Education is little explored topic in Brazil. A significant number of people not had access to Financial Education in their training process and are not in the habit of conducting financial planning. As a consequence, many Brazilians have problems related to finances. From this context, the present article presents a theoretical basis on the subject and the result of an investigation, with high school students, on budget planning, domestic budget, habit of saving, among others comparing the answers between students of two public schools and two private. The research results show that students behave in similar fashion. And, it can be concluded that they do not use the concepts of Financial Education in their day to day.
\end{abstract}

Keywords: Financial Education. High school, Comparactive public and private schools.

\footnotetext{
${ }^{1}$ Mestre em Modelagem Matemática pela UNIJUI. Docente do Instituto Federal de Santa Catarina. E-mail: rosangela.ramon@ifsc.edu.br

${ }^{2}$ Especialista em Matemática Financeira pela UNOCHAPECÓ. E-mail: elianetre@unochapeco.edu.br
} 


\section{REVISTA REAMEC}

Revista da Rede Amazônica de Educação

em Ciências e Matemática

\section{INTRODUÇÃO}

A educação financeira é um assunto pouco abordado e discutido no Brasil, embora a história do país tenha sido marcada por instabilidades econômicas e pela terrível inflação. Segundo Secco (2015) não faz parte da cultura dos brasileiros realizar planejamentos financeiros ou discutir sobre dinheiro com crianças e jovens.

Diante disso, questiona-se: como é possível ser um adulto educado financeiramente se, no processo de formação básica, o tema não é abordado? Para Cerbasi (2011), começar cedo a educar sobre dinheiro e de forma correta pode diferenciar um milionário de um endividado. Ou seja, conhecer como os jovens se relacionam com questões orçamentária no cotidiano e identificar a maneira como os pais envolvem os jovens com as finanças familiares é de extrema importância para saber como direcionar as atividades que vislumbram formar adultos com bom grau de Educação Financeira.

Assim, com o intuito de analisar, por meio da aplicação de questionário, como os adolescentes encaram a Educação Financeira, o presente artigo apresenta os resultados de uma investigação realizada com estudantes do ensino médio, referente à visão que estes têm sobre conceitos relevantes da Educação Financeira: planejamento, orçamento doméstico, hábito de poupar e desejos, apresentando um comparativo entre as respostas dos estudantes de escolas públicas e privadas. Com isso, procura-se evidenciar relações entre o conhecimento e aplicabilidade de conceitos de Educação Financeira no cotidiano.

\section{REFERENCIAIS TEÓRICOS}

Educar financeiramente as crianças e jovens é fundamental para a economia do país e para a qualidade de vida futura. D'Aquino (2008) salienta que o dinheiro existe para dar prazer. Contudo, é fato que existem prazeres que podemos satisfazer hoje; outro só dentro de cinco, quinze ou trinta anos. É necessário, desse modo, planejamento para satisfazer desejos a longo prazo.

Em 2008, o Instituto Data Popular, com apoio da BM\&FBOVESPA, realizou uma pesquisa, em seis capitais, objetivando mensurar o grau de Educação Financeira dos brasileiros. Na pesquisa, foram entrevistadas 1.809 pessoas, sendo estes homens e mulheres com idade entre de 20 a 70 anos, com diferentes rendas e níveis educacionais. 


\section{REVISTA REAMEC}

Revista da Rede Amazônica de Educação

em Ciências e Matemática

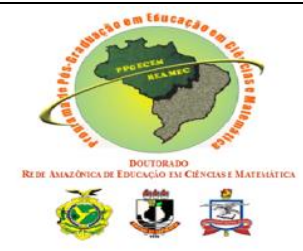

Os resultados da pesquisa revelaram que o grau de Educação Financeira desses brasileiros é baixo. "Vale mencionar que essa inferência apresenta similaridade com os resultados alcançados por outras pesquisas, no mundo, mesmo entre populações de países economicamente desenvolvidos" (BRASIL, 2010, p. 4).

Foram investigadas, na pesquisa de 2008, questões relacionadas a orçamento doméstico, consumo, poupança, sistema financeiro, crédito, investimento, previdência, entre outros. "Essa pesquisa descobriu que 36\% dos entrevistados informaram ter perfil de tipo gastador e apenas $31 \%$ deles guardam dinheiro regularmente para a aposentadoria" (BRASIL, 2010, p. 4). A pesquisa também salienta que uma parcela cada vez maior da renda familiar está sendo destinada para o consumo.

Diante disso, Ferreira (2013) salienta que pais e professores devem encontrar estratégias para preparar as crianças para fazerem boas escolhas, categorizando prioridades de consumo e dando exemplos "os pais precisam ser coerentes nos seus discursos" (FERREIRA, 2013, p. 38).

Para Secco $(2015$, p. 2) "vive-se em uma sociedade não habituada a lidar adequadamente com suas finanças, os transtornos decorrentes disso na economia e na vida do cidadão. Contudo, uma boa educação financeira pode reverter esse quadro". A fim de melhorar o grau de Educação Financeira da população brasileira, em 2010, via decreto, foi definida a Estratégia Nacional de Educação Financeira (ENEF). A Figura 1, apresenta suas finalidades. A ENEF busca contribuir para o fortalecimento da cidadania, proporcionando ações que ajudem na tomada de decisões financeiras. A base para esse fortalecimento financeiro é o planejamento.

Nessa perspectiva, a Organização para Cooperação e Desenvolvimento Econômico (2011) apresentou algumas reflexões sobre o assunto, considerando a Educação Financeira como um processo que possibilita melhorias referentes à relação da sociedade com produtos financeiros. Assim, a informação, formação e orientação possibilitam desenvolver os valores e as competências indispensáveis para fazer escolhas conscientes. 


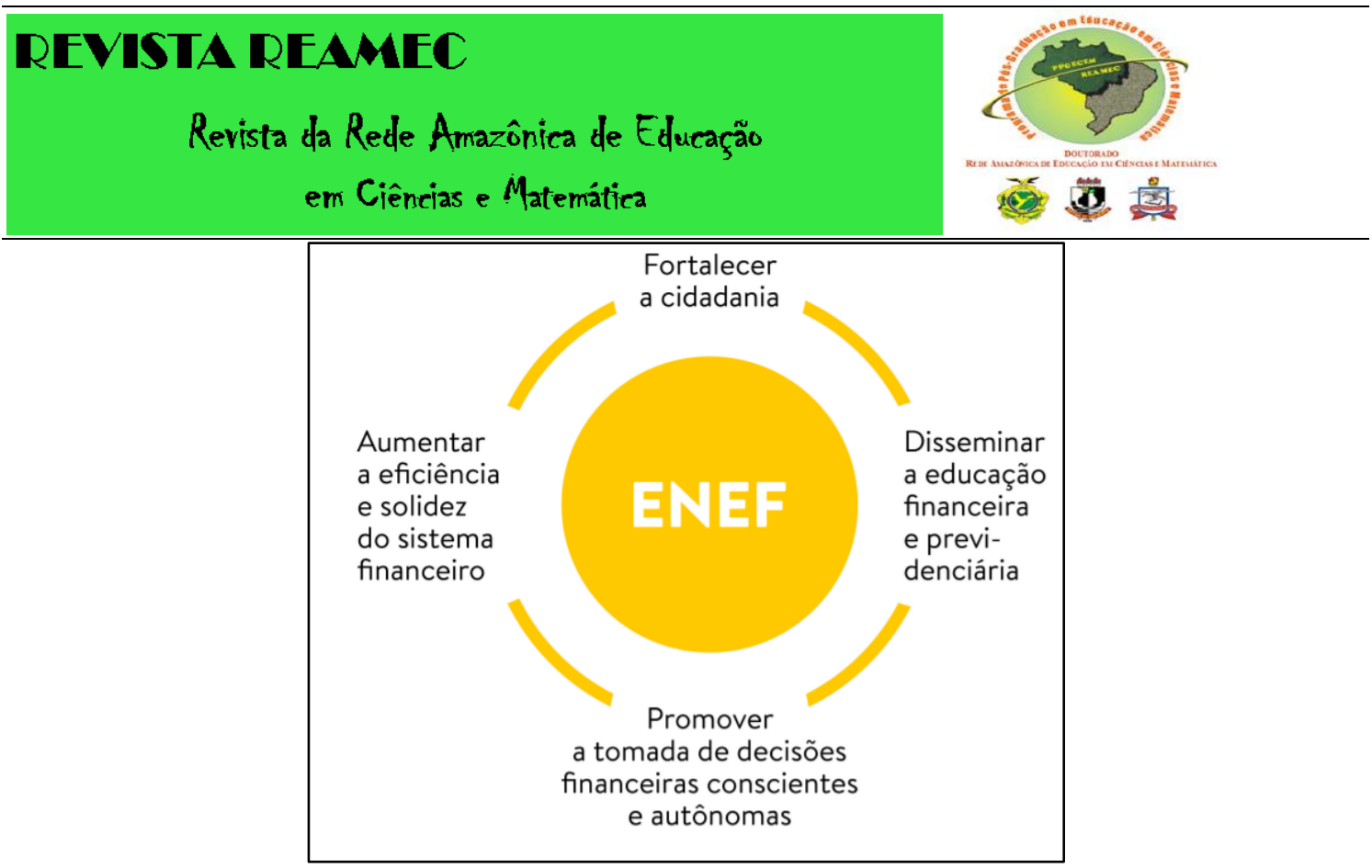

Figura 1: Finalidades da Estratégia Nacional de educação Financeira.

Fonte: http://www.vidaedinheiro.gov.br/wp-content/uploads/2017/04/Infografico-ENEF-0508-1.pdf

A ENEF destaca alguns problemas acarretados quando o nível de Educação Financeira é baixo:

[...] as pessoas não planejam seus gastos no longo prazo, demoram para se preparar financeiramente para a aposentadoria, não estão completamente cientes dos riscos e dos instrumentos para a sua proteção, têm dificuldades em tomar decisões a respeito de empréstimos e investimentos, e são vulneráveis a fraudes (BRASIL, 2010, p. 2).

Para Teixeira (2015), a Educação Financeira vai muito além de economizar. Ela está relacionada à qualidade de vida.

A Educação Financeira não consiste somente em aprender a economizar, cortar gastos, poupar e acumular dinheiro, é muito mais que isso. É buscar uma melhor qualidade de vida tanto hoje quanto no futuro, proporcionando a segurança material necessária para obter uma garantia para eventuais imprevistos (TEIXEIRA, 2015, p. 13).

Nesse sentido, a Educação Financeira tem como princípio desenvolver bons hábitos financeiros, através do planejamento, tomada de decisões, posturas, estudo de casos, visando conquistar melhores condições de vida, mais tranquilidade e segurança financeira. Modernell (2012), em seu site de debates, salienta que atitudes simples como pesquisar preços, pedir descontos, comparar produtos e serviços, pagar à vista, controlar as despesas, evitar desperdícios e dívidas, conhecer os direitos do consumidor, pensar no futuro, manter reservas financeiras para emergências ou oportunidades, evitar realizar 


\section{REVISTA REAMEC}

Revista da Rede Amazônica de Educação

em Ciências e Matemática

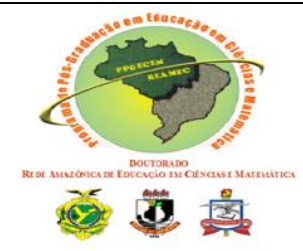

compras por impulso, refletir sobre tentações do crédito fácil, refletem a verdadeira educação financeira.

A Educação Financeira é, nesse sentido, uma ferramenta importante para a realização de desejos e planejamentos dos cidadãos. Por outro lado, deve ser encarada como um conjunto de hábitos financeiros que contribuem para a melhoria das finanças pessoais. As decisões tomadas diariamente terão grande impacto na vida, trazendo consequências no futuro. Conforme Cherobim e Espejo (2011),

o orçamento elaborado a partir de um planejamento capaz de refletir os objetivos e sonhos da família e, principalmente, em consonância à realidade familiar vai possibilitar a contratação de dívidas produtivas, formação de uma riqueza financeira e patrimonial consistente e ainda identificar despesas desnecessárias ou novas oportunidades de obter rendimentos (CHEROBIM, ESPEJO, 2011, p. 42).

Para Domingos (2011), a análise de hábitos, comportamentos e costumes em relação ao dinheiro, o uso do dinheiro que se tem, seja ele pouco ou muito, com responsabilidade e respeito determinará o destino com relação às finanças. $\mathrm{O}$ autor salienta ainda que a Educação Financeira deve ensinar as crianças e jovens que tanto o ganho e o uso do dinheiro devem ser norteados pela ética. D’Aquino (2008) salienta que é difícil fazer escolhas, pois elas resultam em dilemas e consequências. Somente com formação é possível fazer escolhas conscientes.

Embora a ENEF aponte orientações para reduzir o problema, muitos brasileiros continuam apresentando problemas com as finanças. Basta ouvir noticiários nacionais para perceber que a quantidade de pessoas que está endividada no Brasil é alta. Buscando alternativas de soluções para esse tipo de problema, é introduzida a Educação Financeira nas escolas através da Base Nacional Comum Curricular (BNCC). Esta foi homologada pelo MEC em 2018 e enfatiza em seu texto a exploração da Educação Financeira como tema transversal, sendo abordados nos componentes curriculares já existentes. A ideia apresentada no documento é que a Educação Financeira seja abordada por diferentes disciplinas de forma interdisciplinar.

[...] nessa unidade temática é o estudo de conceitos básicos de economia e finanças, visando à educação financeira dos alunos. Assim, podem ser discutidos assuntos como taxas de juros, inflação, aplicações financeiras (rentabilidade e liquidez de um investimento) e impostos. Essa unidade temática favorece um estudo interdisciplinar envolvendo as dimensões culturais, sociais, políticas e psicológicas, além da 
econômica, sobre as questões do consumo, trabalho e dinheiro. É possível, por exemplo, desenvolver um projeto com a História, visando ao estudo do dinheiro e sua função na sociedade, da relação entre dinheiro e tempo, dos impostos em sociedades diversas, do consumo em diferentes momentos históricos, incluindo estratégias atuais de marketing. Essas questões, além de promover o desenvolvimento de competências pessoais e sociais dos alunos, podem se constituir em excelentes contextos para as aplicações dos conceitos da Matemática Financeira e também proporcionar contextos para ampliar e aprofundar esses conceitos (BRASIL, 2018, p. 269).

Dessa maneira, segundo a Base Nacional Comum Curricular (BRASIL, 2018), a Educação Financeira deverá ser contemplada nos componentes curriculares de forma interdisciplinar. No documento, também são apresentadas habilidades a serem desenvolvidas com uso Educação Financeira, tais como:

Resolver e elaborar problemas que envolvam porcentagens, com base na ideia de proporcionalidade, sem fazer uso da "regra de três", utilizando estratégias pessoais, cálculo mental e calculadora, em contextos de educação financeira, entre outros. (BRASIL, 2018, p. 301) Resolver e elaborar problemas que envolvam porcentagens, com a ideia de aplicação de percentuais sucessivos e a determinação das taxas percentuais, preferencialmente com o uso de tecnologias digitais, no contexto da educação financeira (BRASIL, 2018, p. 317).

Aplicar conceitos matemáticos no planejamento, na execução e na análise de ações envolvendo a utilização de aplicativos e a criação de planilhas (para o controle de orçamento familiar, simuladores de cálculos de juros simples e compostos, entre outros), para tomar decisões (BRASIL, 2018, p. 534).

Nessa perspectiva, a inserção da Educação Financeira procura melhorar a relação entre os jovens e as finanças. Fica evidente que não é apenas trabalhar a matemática financeira, mas sim, fazer uso de planejamentos, controles e atitudes. Explorar a Educação Financeira vai, pois, além da matemática financeira.

A mediação docente é considerada por Pessoa, Muniz e Kistemann (2018) como um ambiente favorável de aprendizagem, promovendo no estudante um pensar crítico e que deve considerar aspectos matemáticos e não matemáticos para a tomada de decisão.

Teixeira (2015, p. 13) esclarece que "a administração ineficiente deixa os consumidores vulneráveis a crises financeiras mais graves. Sob a perspectiva de bemestar pessoal, jovens e adultos podem tomar decisões que comprometerão seu futuro...".

A Educação Financeira, quando explorada com coerência, clareza e contextualização, fará diferença no desenrolar da vida de cada estudante. Explorar 


\section{REVISTA REAMEC}

Revista da Rede Amazônica de Educação

em Ciências e Matemática

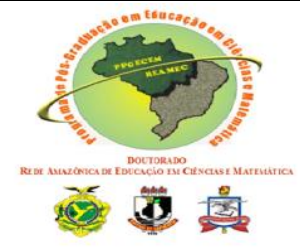

conceitos de Educação Financeira, de forma contextualizada, na escola, poderá contribuir para a melhoria da qualidade de vida no futuro. Discutir questões presentes no cotidiano, como planejamento orçamentário, sustentabilidade, ética, dinheiro, juros, impostos, qualidade de vida é de extrema importância para formação integral dos estudantes. Nesse sentido, Martins (2004, p. 56) alega que a

[...] omissão da escola em relação a noções de comércio, de economia, de impostos e de finanças tem uma consequência perversa: a maioria das pessoas, quando adulta, continua ignorando esses assuntos e segue sem instrução financeira e sem habilidade para manejar dinheiro. As consequências se tornam mais graves se levarmos em conta que ninguém, qualquer que seja sua profissão, está livre dos problemas ligados ao mundo do dinheiro e dos impostos.

Teixeira (2015) ressalta a necessidade de abordar a Educação Financeira desde o início da Escola Básica. Esse mesmo autor define a Educação Financeira como:

[...] um conjunto de informações básicas sobre como fazer a melhor gestão do próprio dinheiro, o que envolve elaborar e acompanhar o orçamento pessoal ou familiar, comprar, poupar, investir e, de modo geral, usar o dinheiro de forma eficaz visando atingir objetivos mais rapidamente (TEIXEIRA, 2015, p. 14).

\section{MATERIAIS E MÉTODOS}

Buscando investigar como os jovens, estudantes de ensino médio (segundos e terceiros anos) concebem fatos relacionados ao planejamento orçamentário, orçamento familiar, hábito de guardar dinheiro, entre outros, foi aplicado um questionário a estudantes de duas escolas públicas e duas escolas particulares da cidade de Xanxerê/SC. O critério de escolha das escolas foi devido à proximidade das mesmas, buscando analisar as diferenças entre os estudantes de escolas públicas e particulares, mas que fossem, na sua maioria, residentes na mesma região.

Foram entrevistados 303 estudantes, com idade variando entre 14 a 20 anos, sendo 147 de escola pública e 156 estudantes de escola pública. O questionário foi elaborado pelas pesquisadoras e é composto por questões objetivas e discursivas. A partir das respostas dos estudantes, foi possível obter as informações analisadas na pesquisa. 


\section{REVISTA REAMEC \\ Revista da Rede Amazônica de Educação \\ em Ciências e Matemática

\section{RESULTADOS E DISCUSSÃO}

Após aplicação de questionário e tabulação dos dados, são apresentados os resultados. Cabe salientar, como indicado na introdução deste artigo, que buscou-se identificar se os estudantes apresentam conhecimentos sobre Educação Financeira e se os colocam em prática.

A idade do público entrevistado, meninos e meninas, variou entre 14 e 17 anos. O Gráfico 1 mostra o número de estudantes das escolas públicas e particulares, e a divisão por gênero.

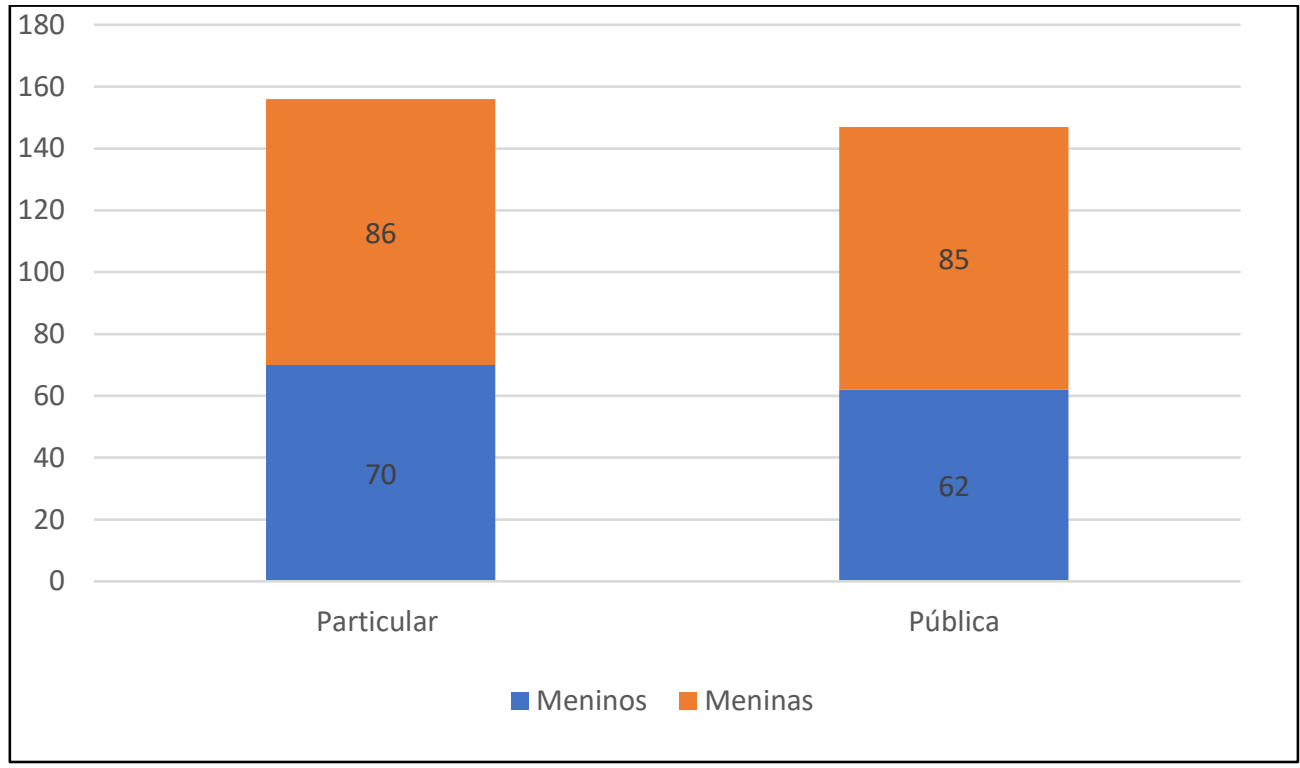

Gráfico 1 - Público entrevistado.

Fonte: Elaborado pelas autoras.

Quando questionados sobre a atuação no mercado de trabalho, cerca de $25 \%$ dos jovens estudantes de escola privada afirmaram exercer alguma atividade remunerada. Já para os estudantes de escola pública, esse percentual passou para $46 \%$. Ou seja, quase a metade dos estudantes entrevistados que frequentam escola pública exercem atividade remunerada.

Como apresentado por Cherobim e Espejo (2011, p. 09), "é muito mais comum hoje você encontrar jovens trabalhando e estudando, ou jovens estão só trabalhando, do que jovens apenas estudando. Essa é a realidade brasileira atual, não adianta lamentar”. 


\section{REVISTA REAMEC}

Revista da Rede Amazônica de Educação

em Ciências e Matemática

$\overline{\mathrm{O} \text { trabalho exercido por estes adolescentes ajuda a complementar a renda familiar e }}$ estruturar a vida financeira.

Para os estudantes que exercem atividade remunerada, foi questionado se os proventos auxiliam no orçamento doméstico de suas famílias. Como podemos verificar no Gráfico 2, a porcentagem dos alunos que exerce algum trabalho remunerado e auxilia no orçamento doméstico é semelhante entre os estudantes das escolas públicas e particulares.

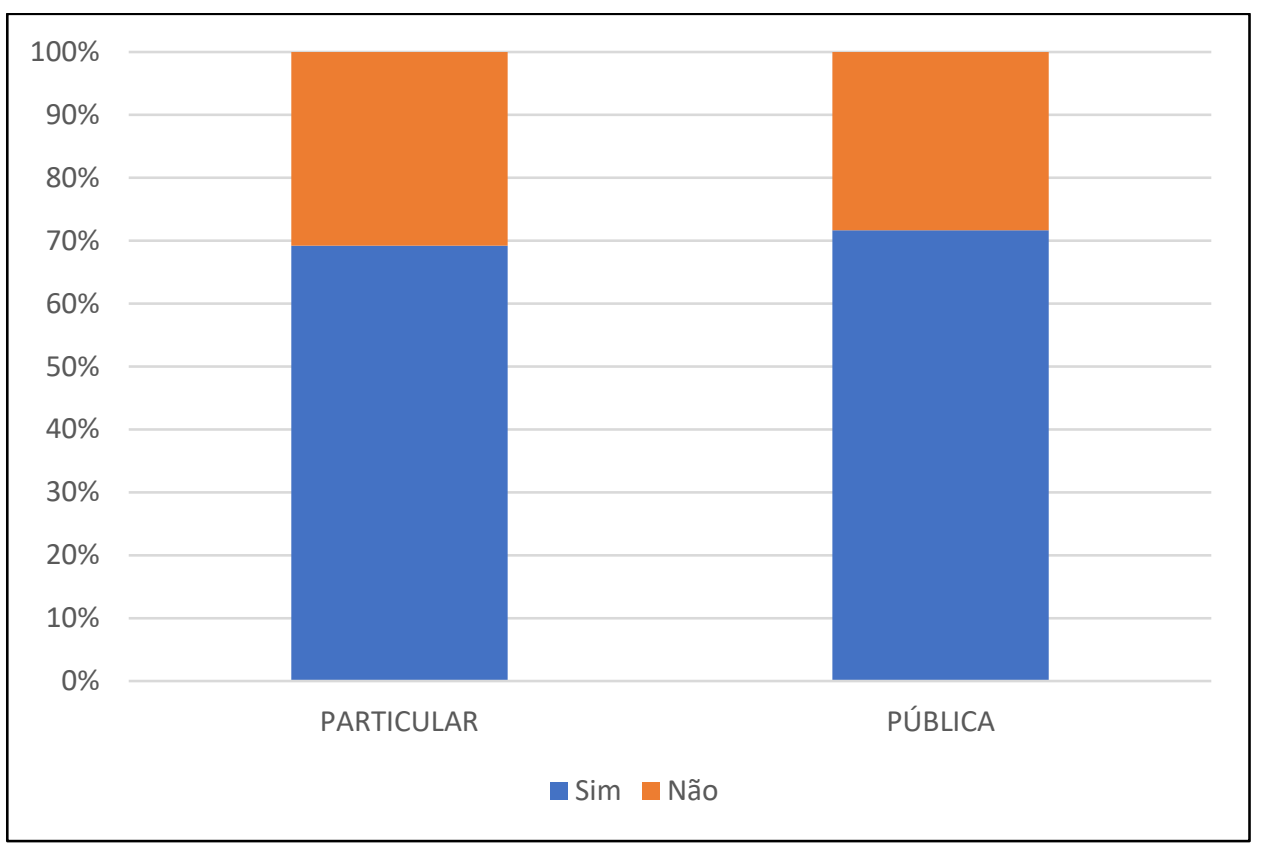

Gráfico 2 - Respostas à pergunta "Você contribui com o orçamento doméstico?"3 Fonte: Elaborado pelas autoras.

Os jovens também foram questionados a respeito de recebimento de mesadas. Nesta questão, 43 estudantes de escola privada afirmaram receber, enquanto que, na escola pública, 26 estudantes informaram que recebem mesada.

Perguntados sobre como gastam seu dinheiro, alunos de escola pública tiveram as seguintes respostas: celular, roupas, calçados, maquiagem, comida, diversão, besteira e ajudam nas contas da casa. As respostas dos estudantes de escola privada revelaram que os alunos gastam seu dinheiro com: celular, roupas, calçados, maquiagem, comida (lanche), festas, jogos e livros. Constata-se que a forma de gastar o dinheiro desses jovens

\footnotetext{
${ }^{3}$ Responderam à pergunta "Você contribui com o orçamento doméstico?" somente os estudantes que afirmaram receber atividade remunerada.
} 


\section{REVISTA REAMEC}

Revista da Rede Amazônica de Educação

em Ciências e Matemática

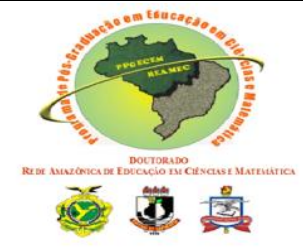

é praticamente as mesmas, ou seja, eles não têm preocupação com contas mensais fixas, exceto por alguns jovens da escola pública que auxiliam nas despesas da casa.

Os jovens que recebem mesada ou salário, quando questionados sobre a expectativa do dinheiro que recebem, afirmam que costumam ficar sem dinheiro, ou seja, o dinheiro recebido não é suficiente para o mês, seja da mesada ou do salário, conforme ilustrado no Gráfico 3.

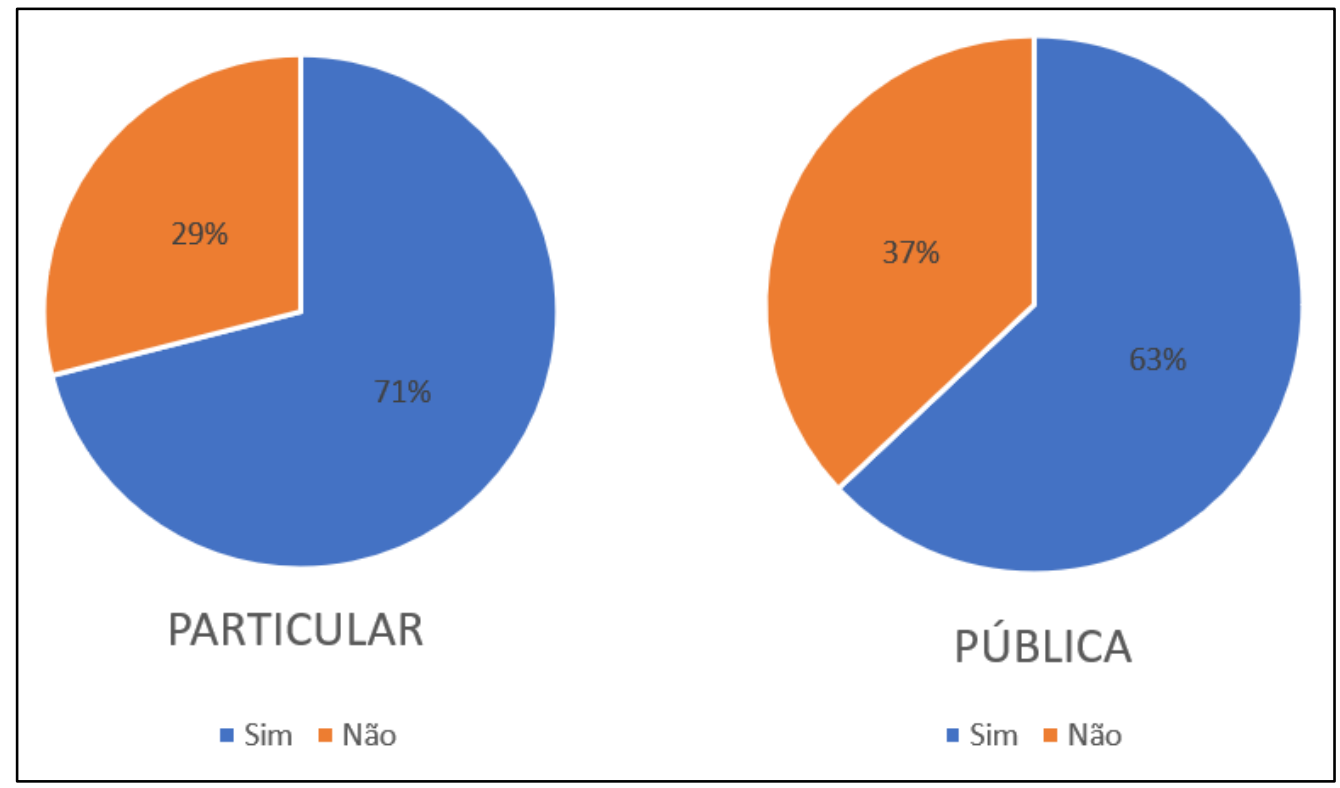

Gráfico 3: Respostas para a pergunta "Normalmente, o seu dinheiro acaba antes do que deveria acabar?". Fonte: Elaborado pelas autoras.

Percebe-se que os estudantes da rede pública possuem um pequeno diferencial nesse quesito. O Gráfico 3 mostra que mais da metade não faz um planejamento sobre os seus gastos, porém o percentual, se comparado com os que estudam em escola particular, é menor. Assim, constata-se que mais de $70 \%$ dos estudantes de escola privada não faz um planejamento sobre o dinheiro que recebe. Como afirmado por Domingos (2011), “compras não planejadas, mal orçadas e realizadas sem as condições adequadas se tornam dívidas”. Bauman (2008) reforça que a cultura consumista pressiona o consumo exagerado, sem a real necessidade, o comprar por comprar. A aquisição de ontem não satisfaz o desejo de hoje. Assim, para satisfazer o novo desejo, procura-se comprar cada vez mais sem levar em conta o orçamento disponível.

A vida de consumidor, a vida de consumo, não se refere à aquisição de posse. Tampouco tem a ver com se livrar do que foi adquirido 


\section{REVISTA REAMEC}

Revista da Rede Amazônica de Educação

em Ciências e Matemática

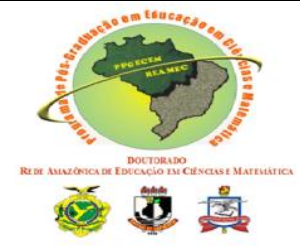

anteontem e exibido com orgulho no dia seguinte. Refere-se, em vez disso, principalmente e acima de tudo, a estar em movimento. Não é a criação de novas necessidades que constitui a principal preocupação da sociedade de consumidores. É o desdém e o desprezo pelas necessidades de ontem e a ridicularização deturpação de seus desejos [...]. A cultura consumista é marcada por uma pressão constante para que sejamos alguém mais (BAUMAN, 2008, p. 126 - 127).

$\mathrm{Na}$ tentativa de bloquear a pressão consumista, deve-se fazer e seguir o planejamento financeiro. Assim, compras realizadas por impulso podem ser evitadas.

Há um excesso de estímulos às vontades cruzando todos os ares e mares. Desconfio que esse exagero se deve à confusão entre o que seja vontade e o que é desejo. Esta é uma discussão que, como tantas outras, vem se arrastando desde a Grécia antiga. No entanto, para fazer uma distinção breve, podemos dizer que o desejo é perene, enquanto a vontade é volátil. Assim, enquanto "vontade é coisa que dá e passa", desejo se sustenta ao longo do tempo (D'AQUINO, 2008, p. 102).

A realização de planejamentos financeiros é indispensável para quem não quer ter problemas orçamentários no futuro.

Agarre em suas mãos o seu próprio destino, e seja responsável por seu sucesso financeiro. Planeje suas receitas e despesas alcance seus sonhos futuros. São atitudes simples, mas que precisam de mudanças comportamentais e que não ocorrem do dia para a noite faça do planejamento e controle financeiro um hábito de vida. Você verá a diferença! (CHEROBIM, ESPEJO, 2011, p. 52).

Quando questionados se consideravam importante ter um planejamento financeiro, $100 \%$ dos estudantes da escola pública afirmaram que sim. Já os estudantes da escola particular atingiram o percentual de $98,7 \%$ para esse questionamento.

$\mathrm{O}$ seu futuro financeiro depende de sua responsabilidade e de sua disciplina no momento presente [...]. Não basta apenas guardar dinheiro, é preciso guardar dinheiro em produtos financeiros que proporcionem segurança e rentabilidade. Não existe mágica [...] (CHEROBIM, ESPEJO, 2011, p. 93).

Mesmo considerando importante ter um planejamento financeiro, existem jovens que não o fazem. Podemos constatar tal afirmação no Gráfico 4. 


\section{REVISTA REAMEC}

Revista da Rede Amazônica de Educação

em Ciências e Matemática
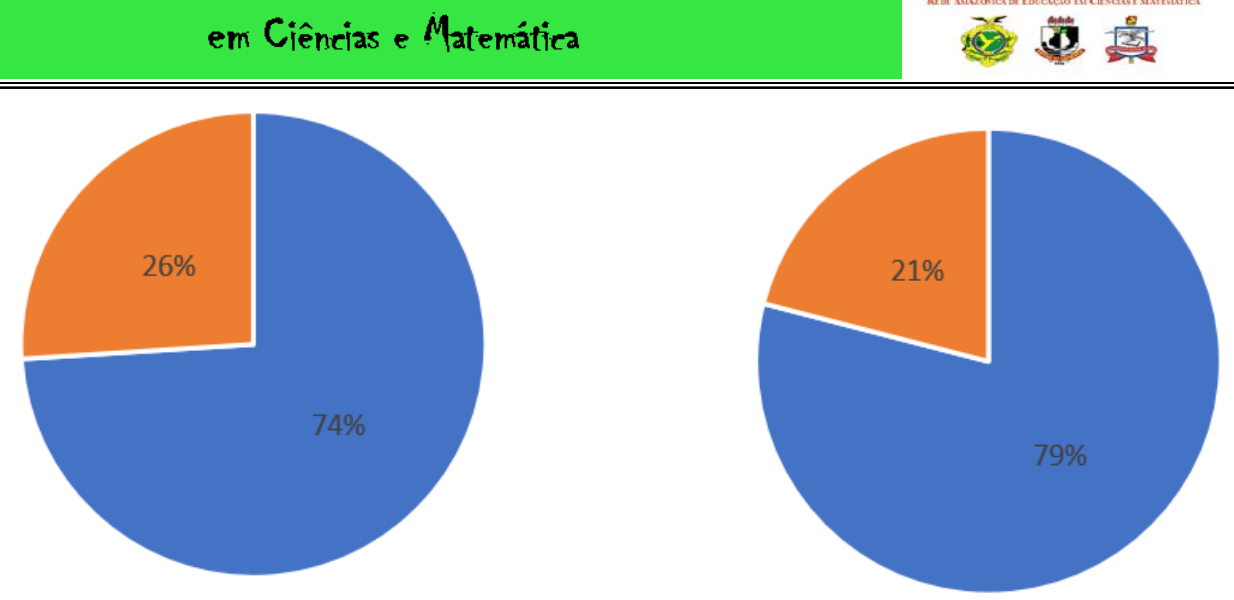

PARTICULAR

PÚBLICA

- Sim = Não

- Sim n Não

Gráfico 4: Respostas para a pergunta "Você faz planejamento com o dinheiro que recebe?".

Fonte: Elaborado pelas autoras.

Comparando os gráficos 3 e 4, percebe-se uma incoerência entre as respostas, pois $74 \%$ dos estudantes de escola privada afirmam fazer planejamento, porém $71 \%$ diz que o dinheiro termina antes do previsto. Assim, pode-se constatar que os estudantes consideram importante planejar seus gastos, mas não o fazem ou então o planejamento não é eficaz.

O mesmo ocorre com os estudantes de escola pública. Cerca de $79 \%$ dos entrevistados afirmam fazer planejamento, porém $63 \%$ afirmam que o dinheiro acaba antes do previsto.

Nesse sentido, destaca-se que é importante ter uma vida financeira controlada e planejada para que não se tenha surpresas futuras. Necessita-se incluir nas tarefas diárias o planejamento, mas que seja um planejamento eficaz. Segundo Cherobim e Espejo (2011, p. 38), "se a cada mês você guardar um pouco do dinheiro com objetivo específico, consegue vislumbrar o horizonte para realização".

No Gráfico 5, pode-se constatar que um número significativo de jovens não apresenta o hábito de guardar dinheiro. Também se percebe que a porcentagem de estudantes que tem o hábito de guardar dinheiro é maior entre os estudantes de escola pública. Cabe ressaltar que responderam a essa pergunta apenas os estudantes que tinham salário proveniente de um emprego ou que recebiam mesadas. 


\section{REVISTA REAMEC}

Revista da Rede Amazônica de Educação

em Ciências e Matemática

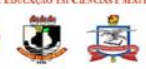

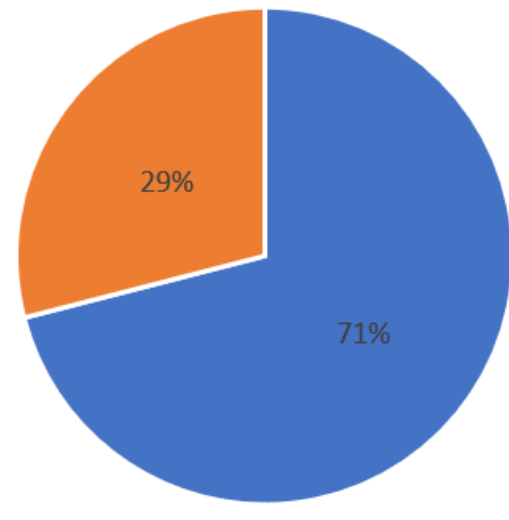

PARTICULAR

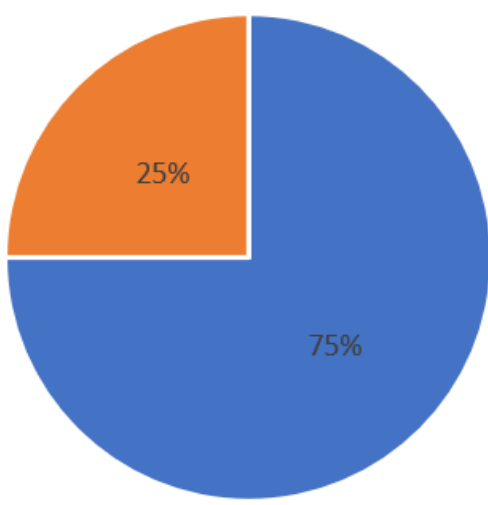

PÚBLICA

$$
\text { - Sim }=\text { Não }
$$

- Sim $=$ Não

Gráfico 5: Respostas para a pergunta “Tem por hábito guardar algum dinheiro?”. Fonte: Elaborado pelas autoras.

Para Cherobim e Espejo (2011, p. 100), “a disciplina é a chave do sucesso na acumulação de capital. Conforme o padrão de vida desejado, o esforço e o sacrifício serão menores ou maiores." Além disso, quando questionados sobre desejos de consumo, as respostas entre os estudantes foram as seguintes:

- Estudantes de escola pública: casa, carro, viajar, ser rico, moto, faculdade, estudar, trabalhar e ter um empreendimento próprio.

- Estudantes de escola privada: viajar para a Disney, computador, carro, celular moderno, casa, ser rico, intercâmbio, faculdade e ter uma fazenda.

É natural do ser humano sonhar e planejar seu futuro. Um projeto de vida auxilia o sucesso pessoal e profissional de cada indivíduo, pois estabelece e clareia os horizontes almejados. O planejamento possibilita monitorar a trajetória e disciplinar as ações de acordo com o cumprimento das metas estipuladas (CHEROBIM, ESPEJO, 2011, p. $51)$.

Respondendo ao questionamento: “O que você está fazendo para que seus desejos de consumo sejam realizados?" as respostas dos entrevistados foram:

- Estudantes de escola pública: estudando, trabalhando, economizando e fazendo cursos.

- Estudantes de escola privada: estudando, economizando. Alguns estudantes afirmaram que estão apenas esperando. 


\section{REVISTA REAMEC}

Revista da Rede Amazônica de Educação

em Ciências e Matemática

Ou seja, possuem alguns desejos de consumo, porém afirmam não tomar atitude alguma para realizar seus desejos. Pode-se observar que os estudantes de escola pública estão mais conscientes da importância de atitudes para realização de seus desejos. Já os alunos de escola particular estão mais acomodados.

A forma mais adequada de iniciar a construção do planejamento e do orçamento é identificar as receitas [...]. Por meio do levantamento das receitas poderá ser definido o seu poder de consumo e seus gastos deverão se adaptar a essa realidade. Não importa a quantidade do seu rendimento; o importante é adequá-lo a sua personalidade, estilo e preferências (CHEROBIM, ESPEJO, 2011, p. 42).

Percebe-se, diante disso, que fazer planejamento de como irá gastar o dinheiro não é muito comum entre as pessoas, porém faz-se necessário para que principalmente os jovens consigam estar com suas contas em dia, comprando o necessário sem gerar dívidas. Dos entrevistados, 115 estudantes de escola privada responderam que fazem planejamento financeiro e 116 jovens das escolas públicas. Outro ponto investigado refere-se ao orçamento familiar. O diálogo em qualquer família é muito importante e, se for relacionado às finanças, acaba auxiliando os jovens para uma melhor compreensão do dinheiro e do seu real valor.

Os jovens foram questionados sobre a existência de diálogo acerca da educação financeira na família. Com relação a esta questão, 123 estudantes de escola particulares responderam que existe esse diálogo, porém 33 jovens responderam que não existir diálogo nas famílias. Na escola pública, 118 jovens afirmam que há diálogo sobre planejamento financeiro na família e 29 deles responderam não existir diálogo sobre o assunto. Mesmo que a maioria dos estudantes afirme a existência de conversas, temos um número considerável de estudantes que não participa de discussões sobre planejamento orçamentário em suas famílias. 


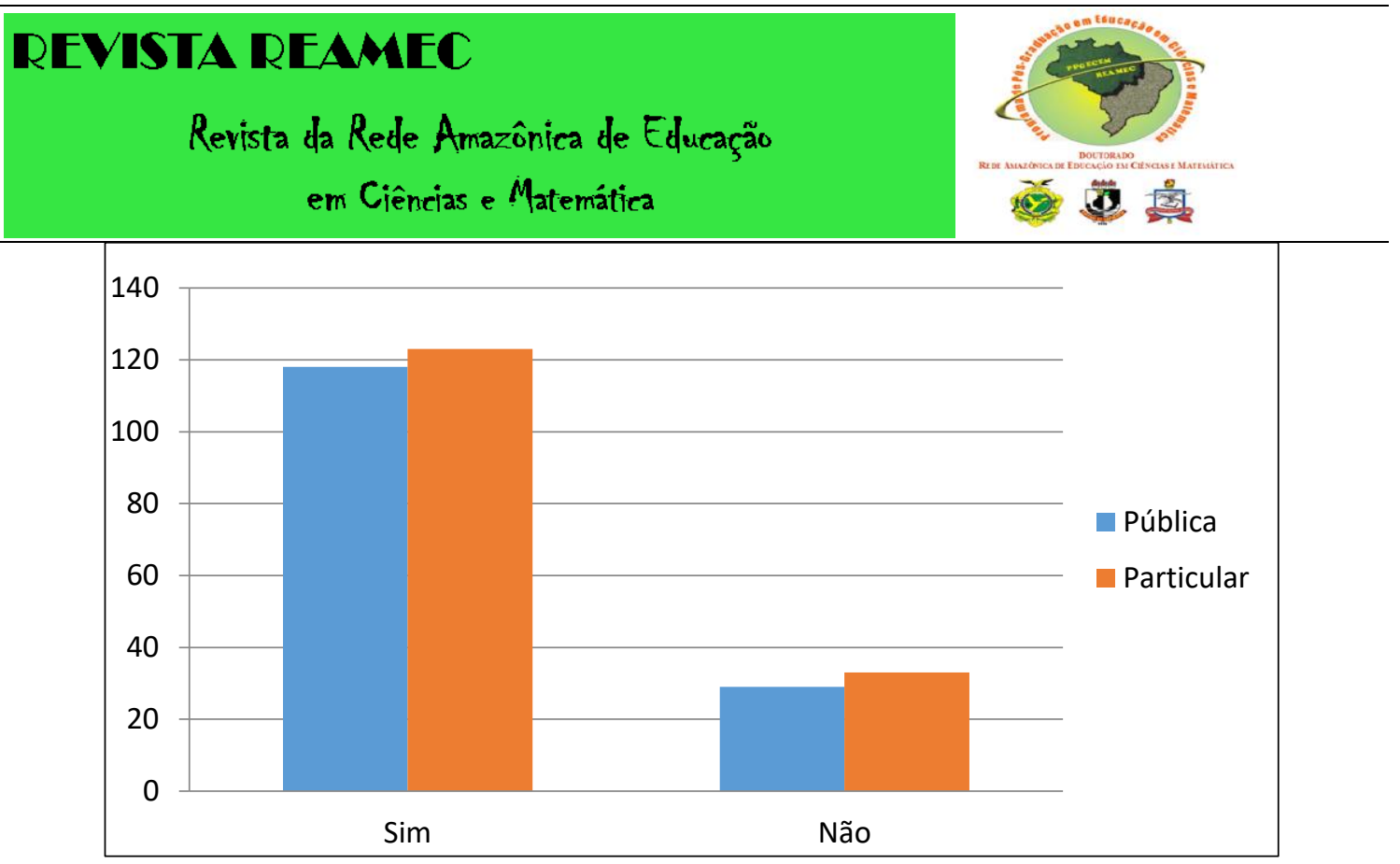

Página | 123

Gráfico 6: Respostas para a pergunta "Na sua família existe diálogo sobre planejamento orçamentário?". Fonte: Elaborado pelas autoras.

Muitos pais acreditam que dinheiro não é assunto de criança e outros transformam esse assunto em um desafio. Educação financeira não significa ensinar a economizar, e sim aprender a manejar o dinheiro de forma correta, a dar importância a fatores que irão promover um futuro financeiro mais digno (SECCO, 2014, p. 7).

Para Ferreira (2013), a Educação financeira das crianças poderá ser abordada em situações cotidianas, enfatizando atividades práticas. Se os pais tiverem noção desses momentos, podem aproveitar para educar financeiramente seus filhos através de reflexões sobre ações realizadas pelos adultos, usando como exemplos erros e acertos.

Kiyosaki (2000) ressalta a importância de explorar a Educação Financeira desde cedo. Para os pais, essa não é uma tarefa fácil. A família, muitas vezes, não se sente preparada para abordar a Educação Financeira, visto que ela própria não possui conhecimento aprofundado sobre o assunto. Assim, os jovens chegam na vida adulta sem a formação mínima necessária para ter uma vida financeira saudável.

Dessa forma, esse tema pode ser trabalhado pelos profissionais da educação, que vão assumir o papel de mediador, educando tanto os jovens como os adultos, a agirem mais com a razão e menos com a emoção com relação às finanças. Assim, ressalta-se a importância de discutir e explorar a educação financeira nas escolas de forma efetiva.

Com base nos dados apresentados na pesquisa, pode-se constatar que não há um diferencial significativo entre estudantes de escolas públicas e particulares no quesito Educação financeira, isto é, os jovens se comportam de maneira similar. 


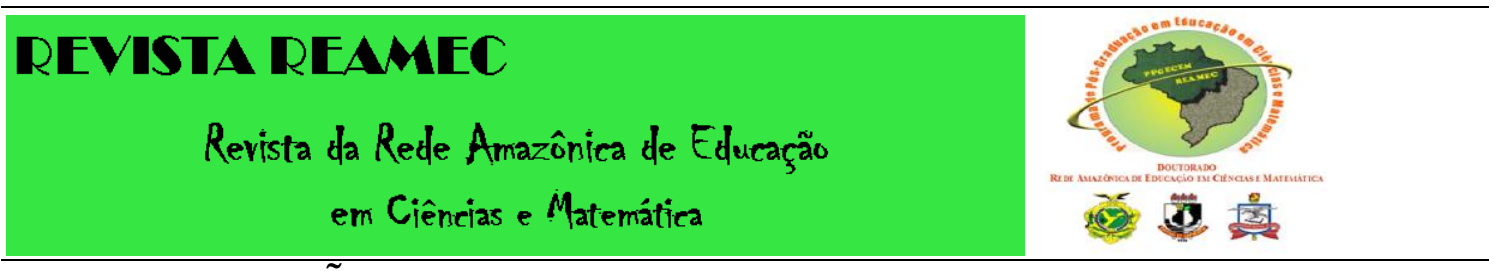

5 CONSIDERAÇÕES

Perante as discussões apresentadas no texto, constata-se fragilidade na formação dos estudantes que estão no ensino médio. Com a introdução efetiva da Educação Financeira, como apresentada na BNCC (2018), a formação em relação ao tema apresentará melhoras e influenciará na qualidade de vida dos estudantes. Pelo resultado da pesquisa, os estudantes das escolas pesquisa (pública e privada) compreendem a importância da Educação Financeira, mas apresentam dificuldade de colocar em prática. Assim, pode-se perceber certa fragilidade na sua formação que recebem em casa ou mesmo na escola.

É aconselhado que a Educação Financeira inicie em casa, pois quanto antes a criança entender e aprender de onde vem o dinheiro e o seu valor, mais fácil será de lidar com finanças. Assim, conforme o sujeito for crescendo, saberá usar de forma consciente o seu próprio dinheiro. Porém, muitas vezes a família não possui um aporte para explorar esse tema. Cabe, então, à escola auxiliar nessa formação. É importante realizar, nas escolas, discussões, atividades, reflexões e situações que explorem conceitos presentes na Educação Financeira, pois, conforme constatado na pesquisa, muitos jovens da rede privada e da rede pública não se posicionam positivamente com as finanças, sendo esses potenciais adultos endividados.

A ENEF incorpora a importância crescente da Educação Financeira no atual contexto do Brasil. Ela lança uma política permanente do Estado para a educação financeira, chamando a ação conjunta dos setores público e privado, com gestão centralizada e execução descentralizada (BRASIL, 2010, p. 10).

É preciso orientar os jovens, pois com atitudes simples pode-se garantir uma melhor qualidade de vida no presente e no futuro. Essas atitudes podem ter início pelo orçamento doméstico e planejamentos financeiros de curto prazo.

A Educação Financeira constitui-se como um dos pilares para a inclusão social dos cidadãos de um país. Nesse sentido, a inserção de temáticas de cunho financeiro nos contextos escolares com propostas interdisciplinares, como propõe a Base Nacional Comum Curricular (BNCC) no Brasil, poderá promover cenários para investigação em ambientes de aprendizagens (PESSOA, MUNIZ, KISTEMANN, 2018, p. 24). 


\section{REVISTA REAMEC}

Revista da Rede Amazônica de Educação

em Ciências e Matemática

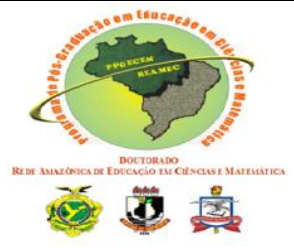

Conforme Teixeira (2015), a boa Educação Financeira promove a gestão dos recursos e o equilíbrio entre a razão e a emoção, além de desenvolver a capacidade de transformar recursos. A exploração da Educação Financeira nas escolas é, pois, um processo novo e lento, mas que precisa ser iniciado para que a vida futura dos estudantes tenha um impacto significativo. D'Aquino (2008) enfatiza que a função da Educação Financeira deve ser criar bases para que, na vida adulta, as pessoas, possam ter uma relação equilibrada e responsável com as finanças.

\section{REFERÊNCIAS}

BAUMAN, Zygmunt. Vida para o consumo: a transformação das pessoas em mercadoria. Rio de Janeiro: Jorge Zahar, 2008.

BRASIL. Ministério da Educação. Base Nacional Comum Curricular (BNCC). Educação é a Base. Brasília, MEC/CONSED/UNDIME, 2018. Disponível em: <http://basenacionalcomum.mec.gov.br/a-base>. Acesso em: 20 mai. 2019.

BRASIL. Banco Central do Brasil. Brasil: Implementando a Estratégia Nacional de Educação Financeira, 2010. Disponível em:

http://www.bcb.gov.br/pre/pef./port/Estrategia_Nacional_Educacao_Financeira_ENEF. pdf. Acesso em: 01 jun. 2018.

CERBASI, Gustavo. Pais inteligentes enriquecem seus filhos. Rio de Janeiro: Sextante, 2011.

CHEROBIM, Ana Paula Mussiszabo. ESPEJO, Márcia Maria dos Santos Bortolocci. Finanças pessoais: conhecer para enriquecer. 2. ed. São Paulo: Atlas, 2011.

D’AQUINO. Cássia. Educação financeira: como educar seus filhos. Rio de Janeiro: Elsevier, 2008.

DOMINGOS, Reinaldo. Ter dinheiro não tem segredo: educação financeira para jovens. São Paulo: DSOP, 2011.

FERREIRA, Ricardo. Educação financeira das crianças e adolescentes. Portugal, Lisboa: Escolar Editora, 2013.

MARTINS, José Pio. Educação financeira ao alcance de todos. São Paulo: Editora C Fundamento Educacional, 2004.

MODERNELL, Álvaro. Afinal, o que é educação financeira? 2012. Disponível em: < http://www.maisativos.com.br/site/artigo-afinal-o-que-e-educacao-financeira/> Acesso em: abril, 2018. 


\section{REVISTA REAMEC}

Revista da Rede Amazônica de Educação

em Ciências e Matemática

PESSOA, C. A. S.; MUNIZ I. Jr.; KISTEMANN, M. A. Jr. Cenários sobre educação financeira escolar: entrelaçamentos entre a pesquisa, o currículo e a sala de aula de Matemática. Revista de Educação Matemática e Tecnológica Ibero-americana, Pernambuco, v. 9, n. 1, p. 1-28, 2018.

KIYOSAKI, R. Pai Rico, Pai Pobre: o que os ricos ensinam a seus filhos sobre dinheiro. Rio de Janeiro: Campos, 60 ed., 2000.

SECCO, R. L.: "Importância da educação financeira na infância: uma revisão de literatura", em Observatorio de la Economía Latinoamericana, Número 203, 2014. Disponível em http://www.eumed.net/cursecon/ecolat/br/14/educacion-financiera.hmtl.

TEIXEIRA, J. Um estudo diagnóstico sobre a percepção da relação entre educação financeira e Matemática Financeira. 2015. 160 f. Tese (Doutorado em Educação) Pontifícia Universidade Católica de São Paulo, São Paulo, 2015.

Submetido em: 14 de junho de 2019.

Aprovado em: 30 de julho de 2019. 